\title{
A plan to nurture "Outstanding engineers" of the Engineering School of characteristics-applied undergraduate colleges and universities and Research to contruct the quality- guaranteed system
}

\author{
Pan Rui,Wang Qiong, ChangJiFeng, WangDaYong \\ Harbin University \\ Zhongxing Road No. 109, Nangang District \\ Harbin city, China \\ panrui999@163.com
}

\author{
ChengPeiFeng, LiShuGong \\ Northeast Forestry University \\ Hexing Road No. 26, Xianfang District \\ Harbin city, China \\ Alanna_nefu@126.com
}

\begin{abstract}
- applied undergraduate education has become an important part of China's higher education. In this paper, aiming at the Engineering program of a specialty-application-focused (SAF) undergraduate colleges and universities, we described our research on nurturing plan and teaching specialty. Based on the research, we construct a quality-guaranteed system of the engineering program of an SAF college or university.
\end{abstract}

Keywords-Applied undergraduate colleges and universities; Outstanding engineers; Training program; Quality assurance system; Building

Applied undergraduate education is an important part of China's higher education. Specialty-application-focused undergraduate colleges and universities are advanced universities with a goal of training talents to adapt to the social and economic developmentneeds. The goal of the "outstanding plan" is to nurture engineers and technicians, who are innovative and adapt to the needs of China's economic and social development. The educational targets in these two goals are consistent. To nurture "outstanding engineers", the engineering program of the SAF colleges should take the social demand as the guide, establish clear training targets, enture the quality and reflect distinctive teaching specialties.

\section{PROBLEMS AND TREND OF THE CURRENT“OUTSTANDING ENGINEER” NURTURING MODEL OF THE ENGINEERING PROGRAM IN THE SAF COLLEGES AND UNIVERSITIES}

The current nurturing system in the engineering school of the SAF colleges and universities has many drawbacks. It shows that the current education system, model and concept doesn't adapt to the society's demand of talents. In the society, people focus on research; despise technology. In the school, imprecise target is developed to nurture talents who are adaptive. applied talents cultivation objective orientation is not allowed. The nurturing model is single and lack of diversity and adaptability, The course design is lack of systematic consideration, Because of the weakness in the Engineering education and practice, it doesn't give enough attention and commitment to nurture students' innovation. It is lack of comprehensive teachers. Teachers emphasize on theories, not practice; they emphasize on classes, not activities outside the class; they emphasize on the in-depth, but not the comprehensive; they emphasize on implanting, not self-study. Also the evaluation system emphasizes on papers, not the design and practice, also ignoring the cultivation of students' innovation ability. Students are lack of opportunities to practice in real working environment. The outcome of internship is not good. They are not provided guarantee of practicing on projects outside school. They show poor hands-on skills and are lack of practical experience. From the production-education-politics perspective, they don't coordinate well. Corporations don't get involved enough into students' nurturing. Based on the social demands, with the real engineering projects as a background, guided by the industry trend, It is necessary to find the path and principles of nurturing "outstanding engineers". It is necessary to innovate on nurturing goals and scopes, education specialties, nurturing plans, and nurturing models.

\section{DESIGN OF NURTURING “OUTSTANDING ENGINEERS”FROM THE ENGINEERING PROGRAM OF THE SAF COLLEGES}

1. Training objectives, standards and specialties of the engineering program of the SAF colleges

(1)Training objectives and standards

The training objective of the engineering program of the SAF colleges is to face the new and advanced technology industry in the modern society to nurture senior technical talents, who can directly solve problems and keep the business running, in the front line of the manufacturing, engineering, construction, management and services. This kind of people has a solid theoretical foundation, and broad professional knowledge. They master the basic knowledge and skills of one technology subject. Their comprehensive capability is high. They also have strong application, promotion and conversion skills in science and technology. They also can use knowledge to solve practical problems in the production. They are talents who are creative and able to adapt to the diverse needs of social development. Their technical thinking ability is strong; they are good at technology application, and able to solve actual technical problems during the production.

(2) Characteristics of running school 
School-running characteristics show in many aspects, like education philosophy, education goals, talent-nurturing model, management mechanism and etc. from the perspective of school-running characteristics, SAF schools want to consider the school tradition, managerial guiding ideology, service direction, regional economic development demand of talents for the specialization, facing the external environment, and etc. Also they want to provide security and intelligence technology support to the region's economic construction. They want to use the social service function effectively, form its scale, create quality and profit, and develop some special characteristics.

2. Research on students' knowledge, capability and quality standards majoring in Engineering of the SAF schools

Use three factors knowledge, capability and quality to define the education goal. Among them,Ability is divided into two aspects of social and professional ability.Social ability mainly refers to Language ability, organization and coordination ability,work ability,professional ability, field processing ability. Professional ability mainly refers to professional logical knowledge, post comprehensive ability, professional (special) ability. Knowledge refers mainly to the basic theory knowledge,professional logical and technical knowledge. Quality includes the basic quality and professional quality. the basic quality refers mainly to political quality, scientific quality, humanistic quality, psychological quality, physical quality.Professional quality refers mainly to professional ethics, team spirit, professional dedication,quality consciousness , safety consciousness , environmental consciousness,legal consciousness.

3. Research on the talent-nurturing process of SAF colleges recruiting by categories and nurturing by stages

Engineering program of the SAF colleges can recruit by the categories of secondary subject. Programs recruiting by categories can nurture students by " $1.5+2.5$ " or " $2+2$ " stages. After 1.5 or 2 years' general knowledge education, students can decide on major directions based on individual's development plan, interest, and specialty.

For the engineering program of the SAF colleges, recruiting and developing by categories reflects the idea of nurturing talents with solid foundation, broad background, creative, and high quality.

Constructing an engineering personnel training system which develops engineers by stages converts the professional education into quality education. It transforms school education into co-operative education. It converts teaching-focused to learning-focused.

4. Set up the large-engineering concept,Carry on the integration and optimization of the training plan

The large-engineering concept is to build a model which blend science, technology, non-technology and engineering practice into one system. The engineering program of the SAF schools should develop new education ideas based on the large-engineering concept. They should help students develop broad views, multi-subject background, good humanistic feelings, and basic scientific knowledge. They should cultivate students to become outstanding engineers. It goes back to projects and emphasizes on developing students' capability of application. It enables students to learn, understand, experience and master the projects, and satisfy the key requirements of engineering education, during the process of practicing. We will break subject classification and design education plan of the engineering program of the SAF schools. Based on different requirements of professions and technical areas, we will develop analysis of knowledge, capability and quality. The professional ability and knowledge of each major should be finely defined. Then build the theoretical and practical education system, and define the course models accordingly. Want to emphasize on quality education during process of teaching, and strengthen the cultivation of students' professional quality during the practical teaching.

5. Make professional training plan

During the process of managing teaching of the Engineering program in an SAF school, training scheme is an important basis. It should reflect the training idea of "regression project", general standards and the characteristics of each major. Engineering bachelor program should reflect engineering knowledge, engineering quality, engineering ability, the spirit of team work and professional ethics. It also should tie closely with the engineering practice. Through integrating the experimental teaching resources and optimizing the teaching content, the ratio of experiments which are comprehensive, full of design and open-ended should increase. Internship includes training on basic engineering skills. It also should include production practice and graduation practice in the enterprise production line. Through practice, students would increase experience of working with real projects, also would improve their engineering practice ability. Graduation project should implement the double tutorial system. Graduation project should be completed in the design and production line of the enterprise, cultivating students' comprehensive engineering skills and communication and cooperation ability. Through participating in teachers' scientific research projects, college students' innovative practice activities, and community activities, we would want to create an engineering practice atmosphere, carrying out the innovation practice, cultivating students' ability to work as a team, and to improve their cultivation quality.

6. Training Mode Reform

(1) from emphasizing scientific basis to paying attention to the engineering practice ability

Engineering school and enterprise shall be connected to cultivate talents. Engineering education will "regress to engineering projects" through the enterprise. Through uniting with several enterprises and building the "Engineering Practice Education Center", students 
engineering practice needs will be met, and their engineering practical skills will be effectively enhanced.

(2) From a single nurturing inside school to in-and-out school nurturing

Many undergraduate "outstanding engineer nurturing plan" practices the " $3+1$ " or " $1.5+2.5$ " model. That is studying in school for 3 years, then get involved in manufacturing, designing, testing and other practices for 1 year accumulatively. Students take some courses in the enterprise. Will invite rich-experienced engineers to teach some courses at school. Gradation projects will link to real manufacturing projects. School and enterprises nurture engineering talents jointly. Students will obtain practical experience and improve their engineering practice level.

(3) From general training to personalized training

The traditional engineering education is completed mostly in the school. Talent cultivation tends to be general. When school and enterprise unite together to promote the "outstanding engineer nurturing plan", it will reflect the program's specialty and the background of the profession. It will design plans individually, and will give full play to students' interest and hobbies. When students do internship in the factory, each factory's products, design, and management are all different. That promotes the cultivation of individual talent, which helps students' development.

\section{III.CHARACTERISTIC OF APPLIED UNDERGRADUATE COLLEGES AND UNIVERSITIES ENGINEERING EXCELLENCE ENGINEERS TRAINING QUALITY GUARANTEE SYSTEM CONSTRUCTION RESEARCH}

1.construction application, double-type faculty

As a SAF undergraduate colleges and universities teacher,should have knowledge application ability, technical implementation ability, practice ability of organization, coordination and cooperation innovation spirit and creative ability of practice. Teachers with theoretical and practical skills should comprise high quality, structure optimization, highly efficient, and have strong learning ability and innovative application, a double-type teachers. In terms of teachers' structure, it should form the status of sharing resources and complementary professional advantage; the teachers' hierarchy structure should be reasonable; the size of academic leader should be suitable and requires less, precise and sharp。In terms of technical position structure , it would not be blindly pursue high title indicator, but it could appropriately expand the proportion of part-time teachers.

2.building a nurturing foundation of SAF talents

Pay attention to the nurturing of practical ability, construct two training foundations in campus and out campus, in order to make the SAF talents develop practical training during the nurturing and learning stage, and enhance their actual application ability. In accordance with the principle of "reproduction of the professional scene, repeat of the basic training skills, highlight the key points, and gradually form a complete set to adapt the size of school and training objectives", we must plan and construct well. For external construction of the practical foundation, according to the different characteristics of each major, we can use a variety of cooperation formats between colleges and enterprises, combine with teaching and enterprise production process, integrate with practice training and employment construction. Strengthen the cultural construction of practice training foundations, and create a good teaching, scientific research and learning environment for the teachers and students.

3. teaching management system

Compare high quality talents' plan with the requirements and standards for personnel training, establish the teaching management system and quality standards, establish and improve the teaching quality assurance system, balance the relationship between the functional departments and departments, between the standard and characteristics. Make the college talents nurturing standard and its corresponding system security; Set the target of personnel training courses and teaching reform.According to general standard of the excellent plan, we formulate principle and the training target for all levels of excellence talentst, and we reconstruct the teaching contents and curriculum system .

4. the teaching quality monitoring system

First, we will establish schools internal teaching quality assurance organization, system and procedures. Various kinds of new teaching evaluation will improve the new teaching internal evaluation mechanism, and fully embodies the outstanding talents training target, such as teaching assessment, professional evaluation, curriculum evaluation, teaching laboratory evaluation, etc. Through establishing and completing the teaching quality evaluation system, it will assess and monitor the classroom teaching, experiment, practice, course design, and graduation design. In order to establish and improve the teaching quality monitoring system, and establish the teaching quality monitoring results running system, we will link up with teaching quality monitoring results and individual teacher assessment, the recruitment of title and position employment, load calculation, outstanding students and scholarship selection etc; Establishing terminal monitoring system , undertaking monitoring and tracking graduate students survey, it will collect ability and quality feedback of employing unit about knowledge of graduates, adjust the teaching plan and process, face the market, and adapt to the needs of society.

Implementing the "outstanding engineers education training plan", we must improve the quality assurance system, "Four Elements" includes "students' resource, teaching, funds and policy” is the most important quality guarantee.

\section{IV.CONCLUSION}

Implementing the "outstanding engineers education training plan" is a systematic project, it is the reform of domino. We should not only learn from western developed countries' higher engineering education experience, but also 
even find out a road to nurturing excellence engineers with the characteristic of a SAF undergraduate colleges and universities engineering, according to their own conditions, the system environment and the characteristics of the historical evolution, the government leading, college implement, and social support trinity.

\section{ACKNOWLEDGMENT}

Fund projects: Heilongjiang province the Twelfth Five-year education scientific planning key topics "characteristics of applied undergraduate colleges and universities engineering" outstanding engineers "training mode of research and practice", Subject Numbers: GBB1211029 ; Heilongjiang province higher education teaching reform project "characteristics applied undergraduate construction implementation" outstanding engineers training plan "research and practice.

\section{REFERENCES}

[1] LiDeCai. Applied undergraduate colleges "outstanding plan" thinking [J]. Journal of northwestern polytechnical university, 2012 (5), 58-62

[2] LinJian. "outstanding engineers education training plan" professional training program to study [J].journal of higher engineering education research, 2011 (4), 10-17

[3] ZhangWenSheng, SongKeRu. "regression project" education concept of implementing the "outstanding engineers education training plan" thinking [J]. Journal of northwestern polytechnical university, 2011 (3)., 77-80

[4] PanZhiHua . New applied undergraduate colleges and universities development strategy thinking [J]. jiangsu higher education, 2003 (6), 29-31

[5] Long Hong-Yi. Research and Analysis of Training Models of Outstanding Engineers [J]. Journal of Heilongjiang College of Education. vol. 31 No. 4, Apr. 2012. 